\title{
Preventive Action of Honey on Methotrexate Induced Intestinal Mucositis in Albino Rats (Immunohistochemical Study)
}

Ali Sultan Al-Refai *

Anatomy Branch - Department of Oral and Maxillofacial Surgery, College of Dentistry, Hawler Medical University, Erbil, Kurdistan Region of Iraq, Iraq

Abstract

Background and Objectives: Gastrointestinal mucositis is a severe and debilitating side effect of chemotherapy Methotrexate (MTX) represents one of the most potent classical anti-tumor drugs. The aim of this study was to determine the preventive effects of honey on the intestinal mucositis caused by methotrexate in rats.

Materials and Methods: In current study forty females Albino rats, weighing 250-300g were used in the study. For the induction of mucositis, $60 \mathrm{mg} / \mathrm{kg}$ of MTX was administered intraperitoneally to each animal in the study group on day 4 . The control animals were intraperitoneally injected by normal saline in the same manner and dose like MTX. At the beginning of the experiment, the rats in each group were randomly divided into two groups: Distilled water treated group and honey treated group (10 animals each). A volume of distilled water equal to honey was given by intragastric gavage tube, while the other group was gavaged with honey at a dose of $(2.5 \mathrm{~g} / \mathrm{kg}) \mathrm{two}$ times daily. The body weight for each rat was measured and then the animals were sacrificed on day 8 . In each experiment, one centimeter of proximal jejunum was removed for histopathological, intestinal morphometry, and immunohistochemical analysis using $\mathrm{Ki}-67$ and $\mathrm{Bcl}-2$ immunolabeling.

Results: The MTX / honey treated group showed significantly $(p<0.05)$ less body weight loss and less histopathological scores than that of MTX / water treated group. But there were non significant differences $(p>0.05)$ were seen in the $\mathrm{Ki}-67$ and $\mathrm{Bcl}-2$ immune expression in comparison with the MTX/water treated group.

Conclusion: Honey at a dose of $2.5 \mathrm{~g} / \mathrm{kg}$ two times daily, produced a partial protection against methotrexate induced mucositis in rat by decreasing the histopathological scores.

Keywords: Mucositis; Jejunum; Honey; Methotrexate

\section{Introduction}

Gastrointestinal mucositis ("mucositis"), is a form of mucosal barrier injury, occur as a severe side effect of many anticancer treatments. Unfortunately such therapy affects all rapidly dividing cells whether neoplastic or not. Since intestinal epithelial cells divide rapidly, chemotherapy can disrupt the intestinal epithelial barrier, leading to mitotic arrest in the crypts and villous blunting. Clinically the use of these drugs is often limited due to its side effects such as severe nausea and widespread gastrointestinal ulceration resulted in diarrhea as a main clinical characteristic [1]. Mucositis increases the morbidity of the patients undergoing cancer treatment, results in extended hospital stays and re- admission rates are also increased [2].

The prevalence of mucositis is variable and appears to be dependent on the type of treatment given as well as the disease that is treated. It occurs in $80-100 \%$ of patients undergoing so called high risk regimens such as radiotherapy to head and neck or high dose chemotherapy [3]. In regimens considered to be low risk for the development of mucosal toxicity, the prevalence of mucositis may be as low as $10-15 \%$, however given the numbers of patients receiving chemotherapy, this is still represents a significant number of patients that are affected by mucositis [4].

Methotrexate (MTX) represents one of the most potent classical anti-tumor drugs. It is one of the folic acid antagonists, it was used at higher doses as a cancer therapy and it is used at much lower doses to treat rheumatic diseases and psoriasis [5]. It is an inhibitor of dihydrofolate reductase, an enzyme that reduces folate to an active form where it acts as a co-factor for the production of nucleic acids essential for DNA synthesis. This effect on reducing DNA formation and cell turnover is responsible for both the therapeutic effect and the more common side effects [6]. Although anticancer drug treatment and radiation therapy have been proven to successfully treat many malignancies, including leukemia and lymphoma, or to be complementary remedies for other cancers, their side effects on normal tissue, especially the hematopoietic system and the epithelium of the gastrointestinal tract, significantly limit their effectiveness [7].

Honey is the substance made when the nectar and sweet deposits from plants are gathered, modified and stored in the honeycomb by honey bees. Honey has antibacterial, anti-viral, anti-fungal and antioxidants properties [8]. In recent times honey has been used to treat burns, surgical wounds, gastric and diabetic ulcers as well as many skin conditions including eczema, psoriasis, and acne [9]. Topically applied honey was also used for treatment of radiation - induced oral mucositis in cancer patients [10].

A recognized indicator of cell mitotic activity is $\mathrm{Ki}-67$, an increase in Ki-67 expression is indicative of increased cell mitotic activity and proliferation. Ki-67 monoclonal antibodies detect a nuclear antigen expressed exclusively at the level of cells in the proliferation phase (phases G1, S, G2 and mitoses), but not in the G0 phase. Therefore, $\mathrm{Ki}-67$ antibodies allow for the immunohistochemical determination of the tissue growth fraction [11]. Bcl-2 is important effecter gene during

*Corresponding author: Ali Sultan Al-Refai, Anatomy Branch - Department of Oral \& Maxillofacial Surgery, College of Dentistry, Hawler Medical University. Erbil, Kurdistan Region of Iraq, Iraq, Tel: 009647504483301; E-mail: alirefai2001@hotmail.com

Received June 16, 2014; Accepted July 18, 2014; Published July 20, 2014

Citation: Al-Refai AS (2014) Preventive Action of Honey on Methotrexate Induced Intestinal Mucositis in Albino Rats (Immunohistochemical Study). J Cytol Histol 5 : 265. doi:10.4172/2157-7099.1000265

Copyright: (c) 2014 Al-Refai AS. This is an open-access article distributed under the terms of the Creative Commons Attribution License, which permits unrestricted use, distribution, and reproduction in any medium, provided the original author and source are credited. 
the apoptosis process and has been reported to prolong the survival of cells by specifically inhibiting apoptosis. The balance between mitotic activity and apoptosis is thought to regulate normal development [12].

Mucositis is a common and important side effect of cancer therapy, identifying agents which can be used to prevent or treat mucositis, diminishing its incidence and severity are the primary concern for researchers and clinicians. For this reason the current study was aimed to investigate the effectiveness of honey as a preventive treatment for the MTX induced mucositis in Albino rat. As variables to evaluate the grade of damage or protection, we used histological and immunohistochemical investigations to clarify its effect on cell proliferation and cell apoptosis.

\section{Materials and Methods}

\section{Rats and housing}

In current study forty females Albino rats, weighing 250-300g were supplied and cared in the Animal House of College of Medicine, Hawler Medical University, Erbil, Kurdistan Region of Iraq. The animals were kept under a standard laboratory conditions and maintained on a 12 hour light/dark cycle at $20 \pm 5^{\circ} \mathrm{C}$, and fed with a standard rat chow and allowed to drink water ad libitum. The research project was approved by the Research Ethics Committee at College of Dentistry, Hawler Medical University under protocol.

\section{Preparation of honey}

Natural unprocessed raw honey was obtained from Merkasour, Kurdistan region of Iraq. The initial solution of honey was freshly prepared by dissolving $50 \mathrm{~g}$ of honey in $40 \mathrm{ml}$ of distilled water (one $\mathrm{ml}$ contain $1.25 \mathrm{~g}$ honey). The mixture was filtered first with a fine muslin cloth and then with filter paper (Whatman no.1).

\section{Induction of mucositis}

Fijlstra et al. $[13,14]$ found that the typical clinical signs of mucositis, such as a decreased food intake, weight loss, and diarrhea, were present in most methotrexate treated rats $(60 \mathrm{mg} / \mathrm{kg})$ from the second day until the fifth day of the experiment, after which rats started to recover. In the fourth day of the experiment, the histological and clinical symptoms of the induced mucositis were most severe. For this reason the animals were scarified four days after intraperitoneal injection of MTX.

\section{Experimental design}

\section{The rats were randomly divided into two groups:}

Control groups: Consist of distilled water treated group and honey treated group (10 animals each). The treatments continue from day one until day eight, at this day all the animals were scarified. In the distilled water treated group, a volume of distilled water equal to honey was given with gavage tube, while the honey-treated group was gavaged with honey at a dose of $2.5 \mathrm{~g} / \mathrm{kg}$ two times daily, with a total of $5 \mathrm{gm} /$ $\mathrm{kg} /$ day [15]. A physiological saline $(0.9 \% \mathrm{NaCl})$ in a similar dose of MTX (60 mg / Kg) interrupt the treatment at day four and administered intraperitoneally instead of MTX.

Study or MTX- treated groups: Consist also of distilled water treated group and honey treated group (10 animals each). Since the honey was used as a preventive treatment for the induced mucositis, it was given four days before MTX injection. The treatments continue from day one until day eight, at this day all the animals were scarified. They were gavaged by distilled water or by honey in a similar way like control group, but intraperitoneal injections of the MTX interrupted the treatment at day four (Figure 1). The body weight for each rat was measured daily for all groups in the study.

\section{Intestinal morphometry}

Villus height was measured from the baseline to the villus tip. Measurements of villus height were determined from 40 villi from four cross sections per tissue segment and a mean value was then obtained. The height were measured from hematoxylin and eosin slides on a light microscope (Olympus, Tokyo, Japan) equipped with a high-resolution digital camera (Microscope Eyepiece Camera UCMOS05100KPA / Ver. 3.2) connected to a computer with an image captured program. The crypts could not be measured in all slides, due to extensive crypt loss. All morphometric measurements were done blindly and were measured in well-orientated sections from digitized images that were evaluated at $\times 10$.

\section{Histopathological analysis}

The animals were sacrificed by over dose of anesthesia on day 8 and the anterior abdominal wall was opened by a midline incision and the proximal jejunum was dissected. In each experiment, one centimeter was removed for histopathological analysis, fixed in $10 \%$ phosphatebuffered formalin, processed, and then embedded in paraffin, cut into $5-\mu \mathrm{m}$ sections, stained with hematoxylin and eosin.

The severity of mucositis was graded using histopathological grading scores of Leitão et al [16]:

0 Normal histological findings.

1 Mucosa: Villus blunting, loss of crypt architecture, sparse inflammatory cell infiltration, vacuolization and edema.

Normal muscular layer.

2 Mucosa: Villus blunting with fattened and vacuolated cells, crypt necrosis, intense inflammatory cell infiltration, vacuolization and edema.

Normal muscular layer.

3 Mucosa: Villus blunting with fattened and vacuolated cells, crypt necrosis, intense inflammatory cell infiltration, vacuolization and edema.

Muscular edema, vacuolization, sparse neutrophil infiltration.

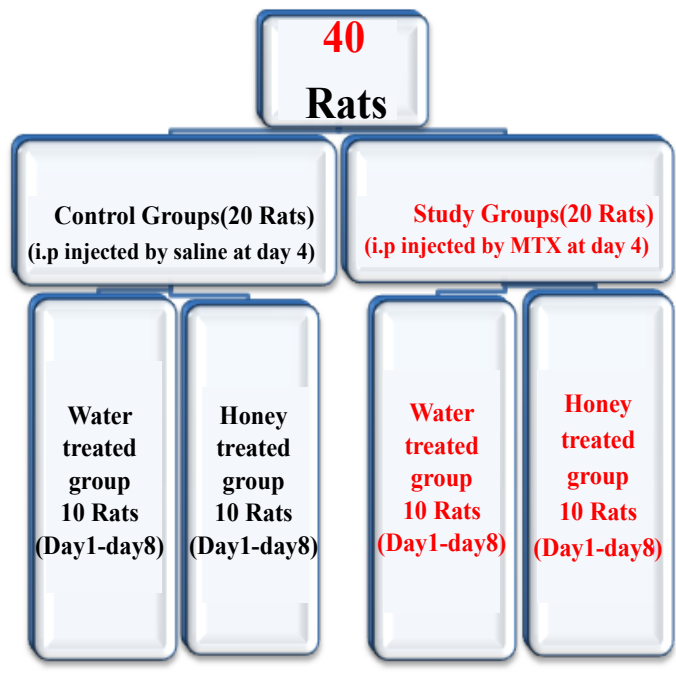

Figure 1: Diagram showing the experimental design of the study. 
Citation: Al-Refai AS (2014) Preventive Action of Honey on Methotrexate Induced Intestinal Mucositis in Albino Rats (Immunohistochemical Study). J Cytol Histol 5: 265. doi:10.4172/2157-7099.1000265

\begin{tabular}{|c|c|c|c|c|c|c|c|c|}
\hline Group & $\begin{array}{c}\text { Day } \\
1\end{array}$ & $\begin{array}{c}\text { Day } \\
2\end{array}$ & $\begin{array}{c}\text { Day } \\
3\end{array}$ & $\begin{array}{c}\text { Day } \\
4\end{array}$ & $\begin{array}{c}\text { Day } \\
5\end{array}$ & $\begin{array}{c}\text { Day } \\
6\end{array}$ & $\begin{array}{c}\text { Day } \\
7\end{array}$ & $\begin{array}{c}\text { Day } \\
8\end{array}$ \\
\hline Saline/ water & $\begin{array}{l}281.03 \\
\pm 0.41\end{array}$ & $\begin{array}{l}283.66 \\
\pm 0.57\end{array}$ & $\begin{array}{c}287.37 \\
\pm 022\end{array}$ & $\begin{array}{c}291.11 \\
\pm 0.42\end{array}$ & $\begin{array}{r}294.74 \\
\pm 0.20\end{array}$ & $\begin{array}{l}297.4 \\
\pm 0.45\end{array}$ & $\begin{array}{l}299.37 \\
\pm 0.21\end{array}$ & $\begin{array}{l}303.34 \\
\pm 0.41\end{array}$ \\
\hline Saline/honey & $\begin{array}{c}283 \\
\pm 0.33 \\
\end{array}$ & $\begin{array}{r}287.55 \\
\pm 0.47\end{array}$ & $\begin{array}{c}293.61 \\
\pm 0.42\end{array}$ & $\begin{array}{l}299.70 \\
\pm 0.75\end{array}$ & $\begin{array}{l}306.25 \\
\pm 0.21\end{array}$ & $\begin{array}{c}312.11 \\
\pm 0.88\end{array}$ & $\begin{array}{r}317.22 \\
\pm 0.32 \\
\end{array}$ & $\begin{array}{l}322.77 \\
\pm 0.48\end{array}$ \\
\hline MTX/water & $\begin{array}{l}262.44 \\
\pm 0.13\end{array}$ & $\begin{array}{l}264.66 \\
\pm 0.622\end{array}$ & $\begin{array}{c}266.11 \\
\pm 0.39\end{array}$ & $\begin{array}{c}269.22 \\
\pm 0.28\end{array}$ & $\begin{array}{r}262.79 \\
\pm 0.33\end{array}$ & $\begin{array}{l}252.05 \\
\pm 0.51\end{array}$ & $\begin{array}{l}239.55 \\
\pm 0.21\end{array}$ & $\begin{array}{c}225.46 \\
\pm 0.56\end{array}$ \\
\hline MTX/honey & $\begin{array}{l}254.32 \\
\pm 0.77\end{array}$ & $\begin{array}{l}257.57 \\
\pm 0.44\end{array}$ & $\begin{array}{l}262.59 \\
\pm 0.28\end{array}$ & $\begin{array}{c}267.355 \\
\pm 0.37\end{array}$ & $\begin{array}{c}263.58 \pm \\
0.22\end{array}$ & $\begin{array}{l}258.53 \\
\pm 0.35\end{array}$ & $\begin{array}{l}249.22 \\
\pm 0.68\end{array}$ & $\begin{array}{l}239.34 \\
\pm 1.44\end{array}$ \\
\hline
\end{tabular}

Table 1: Mean body weights and standard deviation following water or honey administration in female Albino rats post saline or methotrexate injection.

\section{Immunohistochemical stains and analysis using Ki-67 and Bcl-2 immunolabeling}

CryptcellproliferationwasassessedbyKi-67immunohistochemistry, while the apoptosis was assessed by $\mathrm{Bcl}-2$ immunostaining and were performed using monoclonal Mouse Anti-Human Ki-67 Antigen, Clone MIB-1, Code No. M 7240 staining system, and a monoclonal Mouse Anti-Human BcL-2 Oncoprotien Clone 124 Code No 1587 ready to use $\mathrm{N}$-series primary antibody, for use with Dako En Vision ${ }^{\mathrm{TM}}$, En Vision ${ }^{\mathrm{TM}}$ double staining and LASAB ${ }^{\mathrm{TM}} 2$ systems. The staining procedure sections of the instructions included with each detection system were followed. Positive and negative controls were run simultaneously with biopsy specimen.

Positive cells expressing Ki-67 were identified by brown nuclei, while $\mathrm{Bcl}-2$ was demonstrated brown cytoplasmic staining. To ensure the objectivity of the analysis, the evaluation was carried out by two independent observers. Five sections were randomly chosen for each animal. Approximately 1000 cells from cell population were counted by two observers at a magnification of 400x and the percentages of Ki-67 and $\mathrm{Bcl}-2$ positive cells were calculated. All microscopic analyses were performed using a light microscope (Olympus, Tokyo, Japan).

The level of Ki-67 and Bcl-2 expression was evaluated according to the scoring system of Seleit et al. [17]. The application of this system gives a score ranging from 0 to 3 for both degree of positivity: percentage of positively stained cells [(absent: $<1 \%)$, (mild: $1-10 \%)$, (moderate: $10-50 \%)$, (strong: $>50 \%)]$. Statistical analysis: Statistical analysis was performed using Bonferroni Post Hoc test to assess statistical analysis for every individual pair in a group. $P$ value less than or equal to 0.05 was considered statistically significant.

\section{Result}

\section{Body weight}

Before administration of methotrexate, all rats gained body weight. In the saline / water and saline / honey groups, the mean body weight increased in stepwise fashion during the eight days of the experiment (Table 1). Statistical analysis showed that the saline / honey group showed significant increase in the body weight in comparison with the saline / water group during the eight days of the experiment $(\mathrm{p}<0.05)$.

After administration of MTX, the MTX / water and MTX / honey groups experienced significant weight loss in comparison with the control groups $(\mathrm{p}<0.05)$. The severe weight loss and diarrhea was mostly seen associated with the methotrexate / water group at day seven and eight. Statistical analysis showed that the MTX / water group significantly experience more body weight loss in comparison with the body loss of the MTX / honey group $(\mathrm{p}<0.05)$ at day 5, 6, 7, and 8 .

\section{Morphometric and histological analyses}

In the saline / water and saline / honey groups, the jejunum

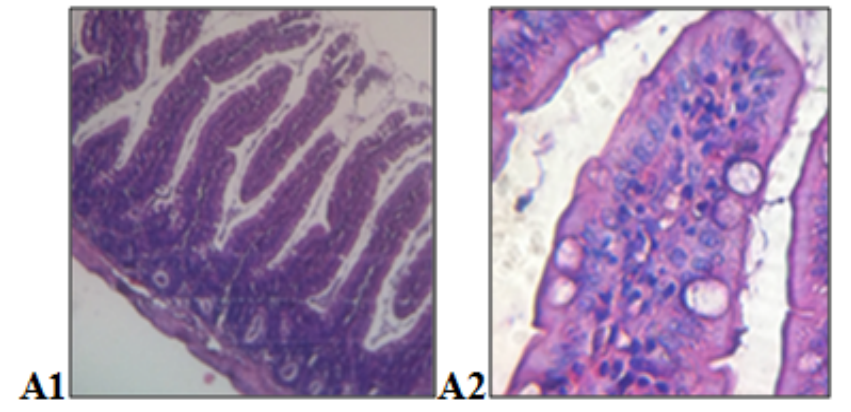

A3
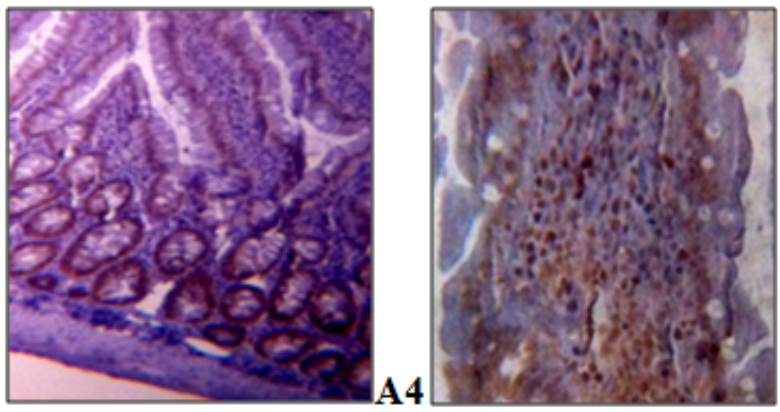

Figure 2: Photomicrograph of saline / water treated group (A1, H\&Ex100) and saline / honey treated group (A2, H\&Ex400) showing that the mucosa of the jejunum forms finger-like projections comprising the epithelium and lamina propria. The predominant cell in the epithelium is composed of columnar cells with basally located nuclei which are evenly aligned. Interspersed between the enterocytes are the oval, mucins secreting goblet cells. Deep cavities, the crypts of Lieberkühn, are present between the villi. The saline / water treated group and the saline/honey treated group showed strong Ki-67 immuno reactivity in nuclei of cells of crypt and villi (A3, immunohistochemistry $\times 100)$, and moderate cytoplasmic reaction to $\mathrm{Bcl}-2$ seen in the epithelia and lamina propria $(A 4$, immunohistochemistry $\times 400)$.

microscopically showed the normal appearance and structure, the mucosa of the jejunum, comprising simple columnar epithelium, forms finger-like projections, tall and cylindrical villi, which protrude into the lumen, and deep cavities, the crypts of Lieberkühn, between the villi. The predominant cell in the epithelium is composed of columnar absorptive enterocyte cells with basally located nuclei which are evenly aligned. Interspersed between the enterocytes are the oval, mucins secreting goblet cells. The lamina propria contains mononuclear cells and extends into villus core and surrounds the crypts (Figure 2A1, A2).

In the MTX / water group, mucositis was observed. Severe mucosal histological damage (crypt loss, villous atrophy, fusion or shortening and a near depletion of goblet cells) were seen. Additionally, the histopathology revealed severe crypt necrosis and inflammatory infiltration within the 
Citation: Al-Refai AS (2014) Preventive Action of Honey on Methotrexate Induced Intestinal Mucositis in Albino Rats (Immunohistochemical Study). J Cytol Histol 5: 265. doi:10.4172/2157-7099.1000265

A1

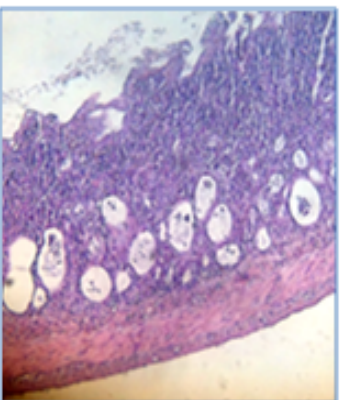

A2



A3

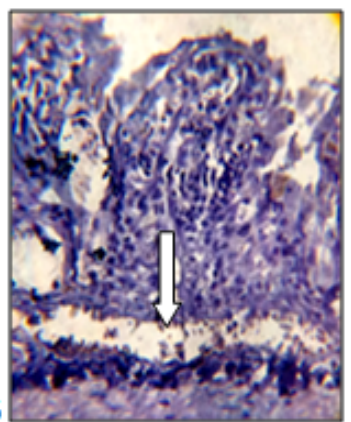

A4

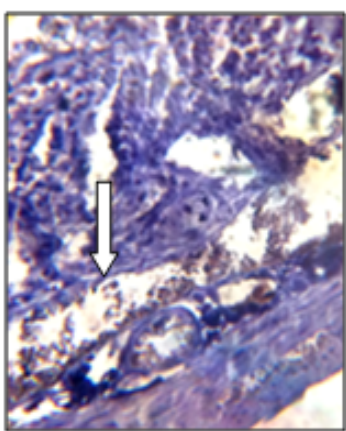

Figure 3: Photomicrograph of the MTX / water treated group showing that the MTX caused mucosal damage in the jejunum. It causes loss or blunting and fusion of villi, heavy infiltration of inflammatory cells and lack of recognizable goblet cells along the crypt-villus axis of the small intestine. Loss of surface epithelium and marked exfoliation of the villi and crypt necrosis (A1 H\&Ex100; A2, H\&Ex400). The MTX / water treated group showed negative immuno reactivity to ki-67 and $\mathrm{Bcl}-2$ (A3, immunohistochemistry $\times 400$; $\mathrm{A} 4$ immunohistochemistry $\mathrm{x} 400$ respectively). The congestion of blood vessels were most severe in the MTX / water treated group (arrows).

\begin{tabular}{|c|c|c|}
\hline Group & Villus height & Damage score \\
\hline Saline/ water & $345 \pm 6.2$ & $0.1 \pm 0.32$ \\
\hline Saline/honey & $349 \pm 9.4$ & $0.1 \pm 0.32$ \\
\hline MTX/water & $152 \pm 4.5$ & $2.4 \pm 0.51$ \\
\hline MTX/honey & $159 \pm 2.8$ & $1.9 \pm 0.42$ \\
\hline
\end{tabular}

Table 2: Mean villus height and damage score with the standard deviation of the jejunum following water or honey administration in female Albino rats post saline or methotrexate injection in all groups in the study.

\begin{tabular}{|c|c|c|}
\hline Group & Ki-67 & Bcl-2 \\
\hline Saline/ water & $56.23 \pm 3.9$ & $39.17 \pm 6.98$ \\
\hline Saline/honey & $58.67 \pm 5.77$ & $39.88 \pm 5.42$ \\
\hline MTX/water & $0.002 \pm 0.003$ & $0.20 \pm 0.41$ \\
\hline MTX/honey & $0.006 \pm 0.004$ & $0.90 \pm 0.47$ \\
\hline
\end{tabular}

Table 3: Mean and standard deviation of the immunohistochemical result of the jejunum following water or honey treatment in female Albino rats post saline or MTX injection in all groups in the study.

lamina propria (Figure 3A1, A2). Villus height decreased significantly ( $>0.05)$ in the study rats compared with control rats (Table 2).

Treatment with honey was partially prevented the villus atrophy, decrease the severity of inflammatory cells infiltration and the number of congested blood vessels, and the villus height and shape were partially restored within on significantly increase in height $(\mathrm{p}>0.05)$ and significant reduction in histopathological scores compared with the MTX / water group $(\mathrm{p}<0.05)$. Honey reduced crypt necrosis as can be clearly observed in representative jejunal section seen in (Figure 4A1, A2).
Immunohistochemical findings: Immunohistochemistry results of the jejunumof control and experimental groups are expressed in Table 3. Statistical analysis showed non significant differences in the number of Ki-67 and Bcl-2 positive cells between saline / water and saline/honey groups $(\mathrm{p}>0.05)$. The number of cells staining positive for Ki-67 andBcl-2 in the MTX / water and MTX / honey groups showed a tendency to decrease significantly $(\mathrm{p}<0.05)$ in comparisonwith the control groups. The MTX / water and MTX / honey groups showed negative expression of both $\mathrm{Ki}-67$ and $\mathrm{Bcl}-2$, with non significant increase in the MTX / honey group (Figure 2A3, A4, Figure 3A3, A4 and Figure $4 \mathrm{~A} 3, \mathrm{~A} 4)$.

\section{Discussion}

The study showed that, MTX administration was accompanied by a significant weight reduction. This result agrees with that of Alamir et al. [18]. They found that the decrease in body weight of rats may be due to intestinal mucositis caused by MTX which altered intestinal absorptive capacity.

In the current study, the MTX / water group lost more weight than rats receiving honey, which was statistically significant. This suggests that animals taking honey lose less weight. This may be because honey contains high concentrations of saccharides which provide a quick source of energy. Biswal et al. [19] found that honey showed to be beneficial in maintaining patient's weight, and $55 \%$ of the honeytreated patients showed either static weight or a weight gain during radiation therapy compared with $25 \%$ in the control patients $(\mathrm{p}<0.05)$.

Motallebnejad et al. [10] support these results and reported that
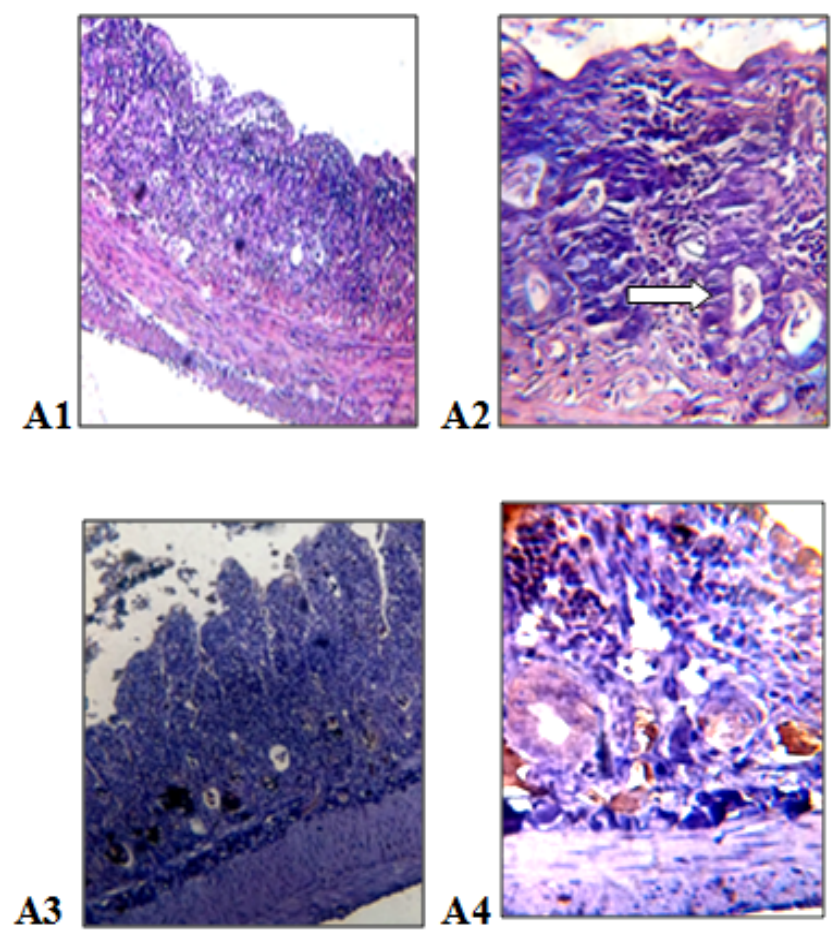

Figure 4 : Photomicrograph of the MTX / honey treated group showing that the MTX also caused mucosal damage in the jejunum, but the crypt necrosis(arrow) and congestion were less severe than the MTX / water treated group (A1, H\&Ex100; A2, H\&Ex400).. The MTX/honey treated group also showed negative immuno reactivity to ki-67 and $\mathrm{Bcl}-2$ (A3, immunohistochemistry $\mathrm{x} 100 ; \mathrm{A} 4$, immunohistochemistry $\mathrm{x} 400$ respectively). 
patients in the honey group had significantly less weight loss with the average weight loss for the honey group of $1 \mathrm{~kg}$ compared with $6.3 \mathrm{~kg}$ in the control group $(\mathrm{p}<0.001)$. But Parsons [20] found that patients taking honey appeared to have slightly less weight loss than those receiving standard treatments alone but this did not reach statistical significance.

In the saline / honey group, the jejunum microscopically showed the normal appearance and structure. This indicates the non-cytotoxic effects of honey to normal cells. Erejuwa et al. [21] also found that honey is non toxic to normal cells.

The results also showed that honey in the MTX / honey group decrease significantly the damage score in comparison with the MTX / water group. The severe crypt necrosis and inflammatory infiltration within the lamina propria, villous atrophy, fusion or ulcerations were seen mostly associated with the MTX / water group. This could be due to the antibacterial, anti-viral, anti-fungal and antioxidants properties of honey [8]. In addition, several data indicated that the honey flavonoid markedly suppressed the release of pro-inflammatory cytokines including TNF- $\alpha$ and IL-1 $\beta$ [22]. Honey also suppressed edema and leukocyte (monocyte and neutrophil) infiltration [23]. Honey beneficial role also has been endorsed to its boosting of the immune system [24]. The data indicate that honey can modulate the molecular processes of initiation, promotion, and progression stages [21]. Tonks et al. [25] found that the effect of honey may depend upon its ability to up regulate production of cytokines, such as tumor necrosis factor and interleukins that result in formation of new blood vessels, and the anti-inflammatory effects can be attributed to activation of immune white blood cells particularly, the giant monocytes which represent the first defense line of the body. The natural honey could activate the giant monocyte up to $50 \%$ in addition to increase the activity of lymphocytes.

Honey contain several biologically active constituents such as flavonoids and phenolic compounds, vitamins, minerals (calcium, iron, zinc, potassium, phosphorous, magnesium, selenium, chromium, manganese), amino acids, proteins, enzymes including glucose oxidase, invertase and catalase and carotenoids as wellas folic acids. Its enzymes and tissue nutrition minerals and vitamins that help repair tissue directly [26].

Some of the flavonoids and phenolic compounds that have been identified in honey include chrysin, kaempferol, quercetin, pinobanksin, pinocembrin, luteolin, apigenin, genistein, naringenin, hesperetin, $p$-coumaric acid, gallic acid, ellagic acid, ferulic acid, syringic acid, caffeic acid and vanillic acid [27]. They may accelerate the healing process by its anti-oxidant and free radical scavenging ability $[9,28]$.

In addition to that, foods rich in saccharides would increase the ability of cells for growth and renewal. The natural honey, in general, is considered as one of the richest foods in its saccharide contents which could be around 70\% - 80\% [29].

A statistically no significant difference $(\mathrm{P}>0.01)$ present between saline / water and saline / honey group in terms of the rate of proliferation and antiapoptosis. This is because honey is non-cytotoxic to normal cells [21].

The number of cells staining positive for Ki-67 andBcl-2 in the MTX/water and MTX / honey groups showed a tendency to decrease significantly $(\mathrm{p}<0.05)$ in comparison with the control groups. MTX cause decreased DNA synthesis and cellular replication [30] and activates the apoptotic pathway [31].
For comparison, no other studies were found to evaluate the effect of honey on intestinal mucositis. Several studies explained that honey can accentuate the effect of chemotherapy and can be used for treatment of cancer. Using various cancer cell lines, honey has been documented to induce cell cycle arrest. Chrysin and several other phenolics such as quercetin and kaempferol which are found in large quantities in honey have been shown to arrest cell cycle at various phases of cell cycles in human melanoma, renal, cervical, hepatoma, colon and oesophageal adenocarcinoma cell lines. The anti-proliferative effect of honey on cancer cells was also shown to be associated with increased generation of ROS accompanied by DNA fragmentation and apoptosis $[32,33]$.

\section{Conclusion}

The MTX / honey treated group showed significantly $(\mathrm{p}<0.05)$ less body weight loss than that of MTX / water treated group. Honey can partially protect the jejunum from MTX-induced cytotoxicity, attenuate or decrease the associated injury by significant decrease in the histopathological scores, but a non significant increase in the Ki67 and Bcl-2 immuno expression were seen in comparison with non honey MTX treated group.

\section{References}

1. Shih A, Miaskowski C, Dodd MJ, Stotts NA, MacPhail L (2003) Mechanisms for radiation-induced oral mucositis and the consequences. Cancer Nurs 26 : 222-229.

2. Elting LS, Cooksley C, Chambers M, Cantor SB, Manzullo E, et al. (2003) The burdens of cancer therapy. Clinical and economic outcomes of chemotherapyinduced mucositis. Cancer 98: 1531-1539.

3. Keefe DM, Brealey J, Goland GJ, Cummins AG (2000) Chemotherapy for cancer causes apoptosis that precedes hypoplasia in crypts of the small intestine in humans. Gut 47: 632-637.

4. Rubenstein EB, Peterson DE, Schubert M, Keefe D, McGuire D, et al. (2004) Clinical practice guidelines for the prevention and treatment of cancer therapyinduced oral and gastrointestinal mucositis. Cancer 100: 2026-2046.

5. Benedek TG (2010) Methotrexate: from its introduction to non-oncologic therapeutics to anti-TNF-Ît. ClinExpRheumatol 28: S3-8.

6. Deeming GM, Collingwood J, Pemberton MN (2005) Methotrexate and oral ulceration. Br Dent J 198: 83-85.

7. Jin S (2012) Role of p53 in Anticancer Drug Treatment- and Radiation-Induced Injury in Normal Small Intestine. Cancer Biol Med 9: 1-8.

8. Sampath Kumar KP, Bhowmik D, Chiranjib, Biswajit,Chandira MR (2010) Medicinal uses and health benefits of Honey: An Overview. J Chem Pharm Res 2: 385-395.

9. Molan PC (2006) The evidence supporting the use of honey as a wound dressing. International Journal of Lower Extremity Wounds 5: 40-54.

10. Motallebnejad M, Akram S, Moghadamnia A, Moulana Z, Omidi S (2008) The effect of topical application of pure honey on radiation-induced mucositis: a randomized clinical trial. J Contemp Dent Pract 9: 40-47.

11. LazÄfr D, TÄfban S, Sporea I, Dema A, Cornianu M, et al. (2010) Ki-67 expression in gastric cancer. Results from a prospective study with long-term follow-up. Rom J MorpholEmbryol 51: 655-661.

12. Ribeiro DA, Salvadori DM, Marques ME (2005) Abnormal expression of bcl2 and bax in rat tongue mucosa during the development of squamous cell carcinoma induced by 4-nitroquinoline 1-oxide. Int J ExpPathol 86: 375-381.

13. Fijlstra M, Rings EHHM, Verkade HJ, van Dijk TH, Kamps WA, et al. (2011) Lactose maldigestion during methotrexate-induced gastrointestinal mucositis in a rat model. Am J PhysiolGastrointest Liver Physiol 300: 283- 291.

14. Fijlstra M, Tissing WJE, Verkade HJ, Rings EHHM (2013) Parenteral feeding during methotrexate-induced gastrointestinal mucositis prevents weight loss in the rat. e- SPEN Journal 8: e95-e99.

15. Chandane RD, Jaju JB, Ghadlinge MS, Bhosale RR, Chandrakapure AR (2013) Effect of honey on hepatotoxicity induced by antitubercular drugs in albino rats. International Journal of Basic \& Clinical Pharmacology 2: 177- 181. 
Citation: Al-Refai AS (2014) Preventive Action of Honey on Methotrexate Induced Intestinal Mucositis in Albino Rats (Immunohistochemical Study). J Cytol Histol 5: 265. doi:10.4172/2157-7099.1000265

Page 6 of 6

16. Leitão RF, Brito GA, Oriá RB, Braga-Neto MB, Bellaguarda EA, et al. (2011) Role of inducible nitric oxide synthase pathway on methotrexate-induced intestinal mucositis in rodents. BMC Gastroenterol 11: 90

17. Seleit IA, Asaad N, Maree A, Abdel Wahed M (2010) Immunohistochemical expression of p53 and $\mathrm{Ki}-67$ in cutaneous lupus erythematosus. J Egypt Women DermatolSoc 7: 5-15.

18. Alamir I, Boukhettala N, Aziz M, Breuillé D, Déchelotte P, et al. (2010) Beneficial effects of cathepsin inhibition to prevent chemotherapy-induced intestinal mucositis. ClinExplmmunol 162: 298-305.

19. Biswal BM, Zakaria A, Ahmad NM (2003) Topical application of honey in the management of radiation mucositis: a preliminary study. Support Care Cancer 11: $242-248$

20. Parsons E (2011) Manuka Honey: An Investigation into the Effect of Manuka Honey on Oral Mucositis in Patients Receiving Radiation Therapy to the Head and Neck. (Thesis, Bachelor of Health Sciences with Honours). University of Otago, Dunedin, New Zealand.

21. Erejuwa OO, Sulaiman SA, Wahab MS (2014) Effects of honey and its mechanisms of action on the development and progression of cancer. Molecules 19: 2497-2522.

22. Candiracci M, Piatti E, Dominguez-Barragan M, Garcia-Antras D, Morgado B, et al. (2012) Anti-inflammatory activity of a honey flavonoid extract on lipopolysaccharide-activated N13 microglial cells. J Agric Food Chem 60: 12304-12311.

23. Leong AG, Herst PM, Harper JL (2012) Indigenous New Zealand honeys exhibit multiple anti-inflammatory activities. Innate Immun 18: 459-466.

24. Meda A, Lamien CE, Millogo J, Romito M, Nacoulma OG (2004) Therapeutic uses of honey and honeybee larvae in central Burkina Faso. J Ethnopharmacol 95: 103-107.
25. Tonks AJ, Cooper RA, Jones KP, Blair S, Parton J, et al. (2003) Honey stimulates inflammatory cytokine production from monocytes. Cytokine 21: 242-247.

26. Robson V, Dodd S, Thomas S (2009) Standardized antibacterial honey (Medihoney) with standard therapy in wound care: randomized clinical trial. $J$ AdvNurs 65: 565-575.

27. Sergiel I, Pohl P, Biesaga M (2014) Characterisation of honeys according to their content of phenolic compounds using high performance liquid chromatography/ tandem mass spectrometry. Food Chem 145: 404-408.

28. Alzahrani HA, Boukraa L, Bellik Y, Abdellah F, Bakhotmah BA, et al. (2012) Evaluation of the antioxidant activity of three varieties of honey from different botanical and geographical origins. Glob J Health Sci 4: 191-196.

29. Gharzouli K, Amira S, Gharzouli A, Khennouf S (2002) Gastroprotective effects of honey and glucose-fructose-sucrose-maltose mixture against ethanolindomethacin-, and acidified aspirin-induced lesions in the rat. ExpToxicolPathol 54: 217-221.

30. Benedek TG (2010) Methotrexate: from its introduction to non-oncologic therapeutics to anti-TNF-Ît. Clin Exp Rheumatol 28: S3-8.

31. Sonis ST (2004) Pathobiology of mucositis. Semin Oncol Nurs 20: 11-15.

32. Vidia Priyadarsini VR, Senthil Murugan R, Maitreyi S, Ramalingam K, Karunagaran D, et al. (2010). The flavonoid quercetin induces cell cycle arrest and mitochondria-mediated apoptosis in human cervical cancer (HeLa) cells through p53 induction and NF-kappaB inhibition. Eur J Pharmacol 649:84-91.

33. Song W, Dang Q, Xu D, Chen Y, Zhu G, et al. (2014) Kaempferol induces cell cycle arrest and apoptosis in renal cell carcinoma through EGFR/p38 signaling Oncol Rep 31: 1350-1356. 